\title{
Verzeichnis der benutzten Bezeichnungen
}

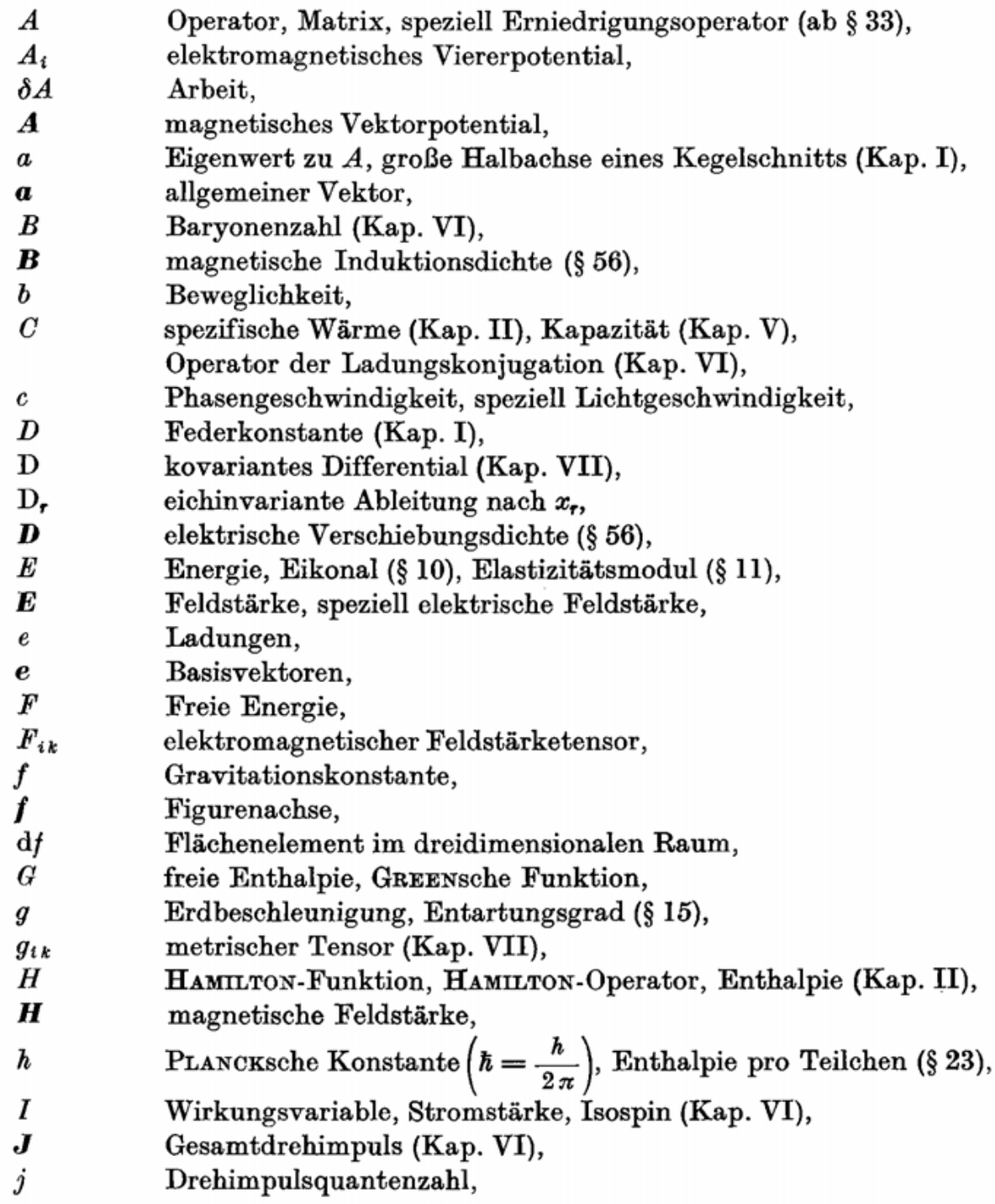




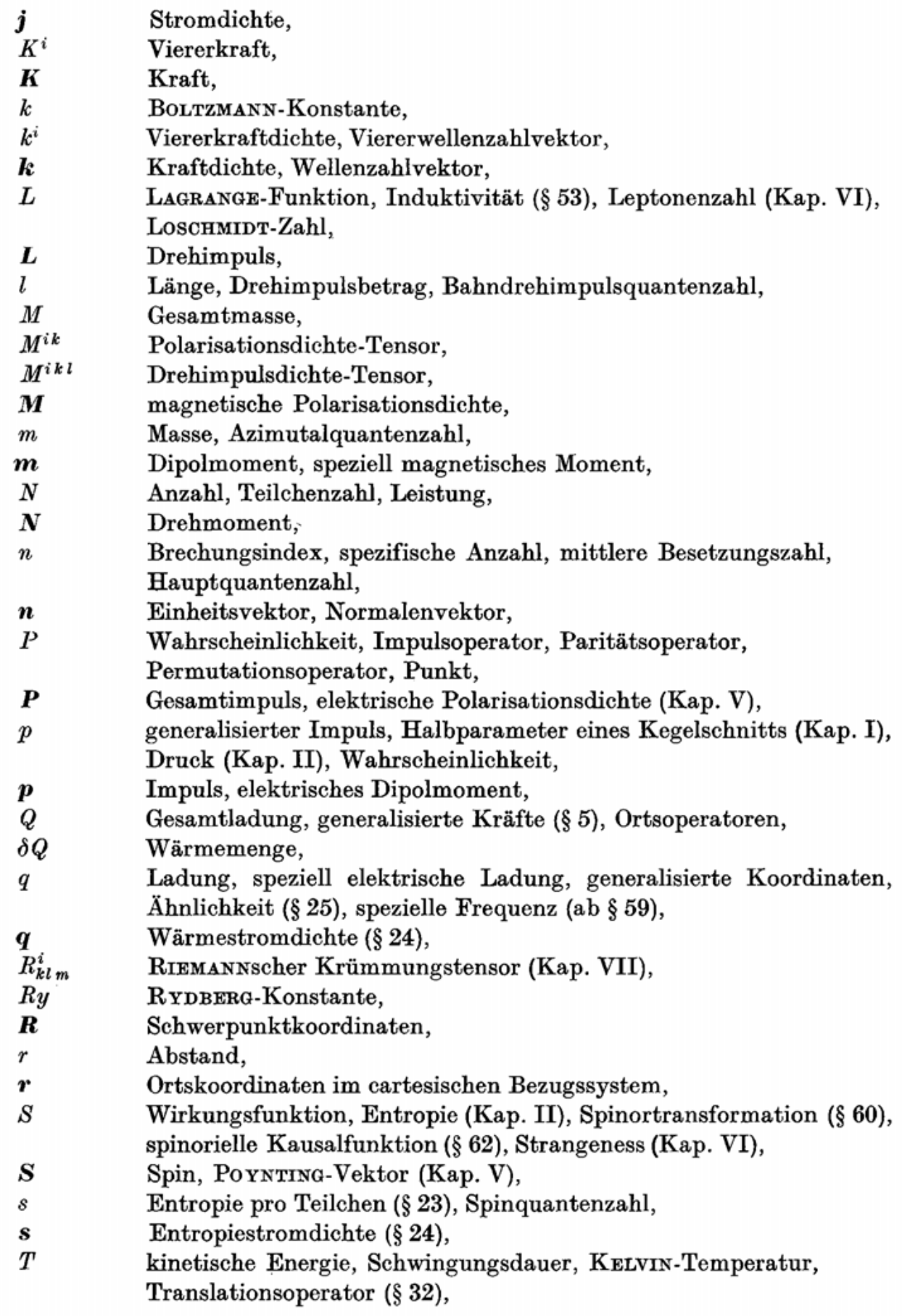




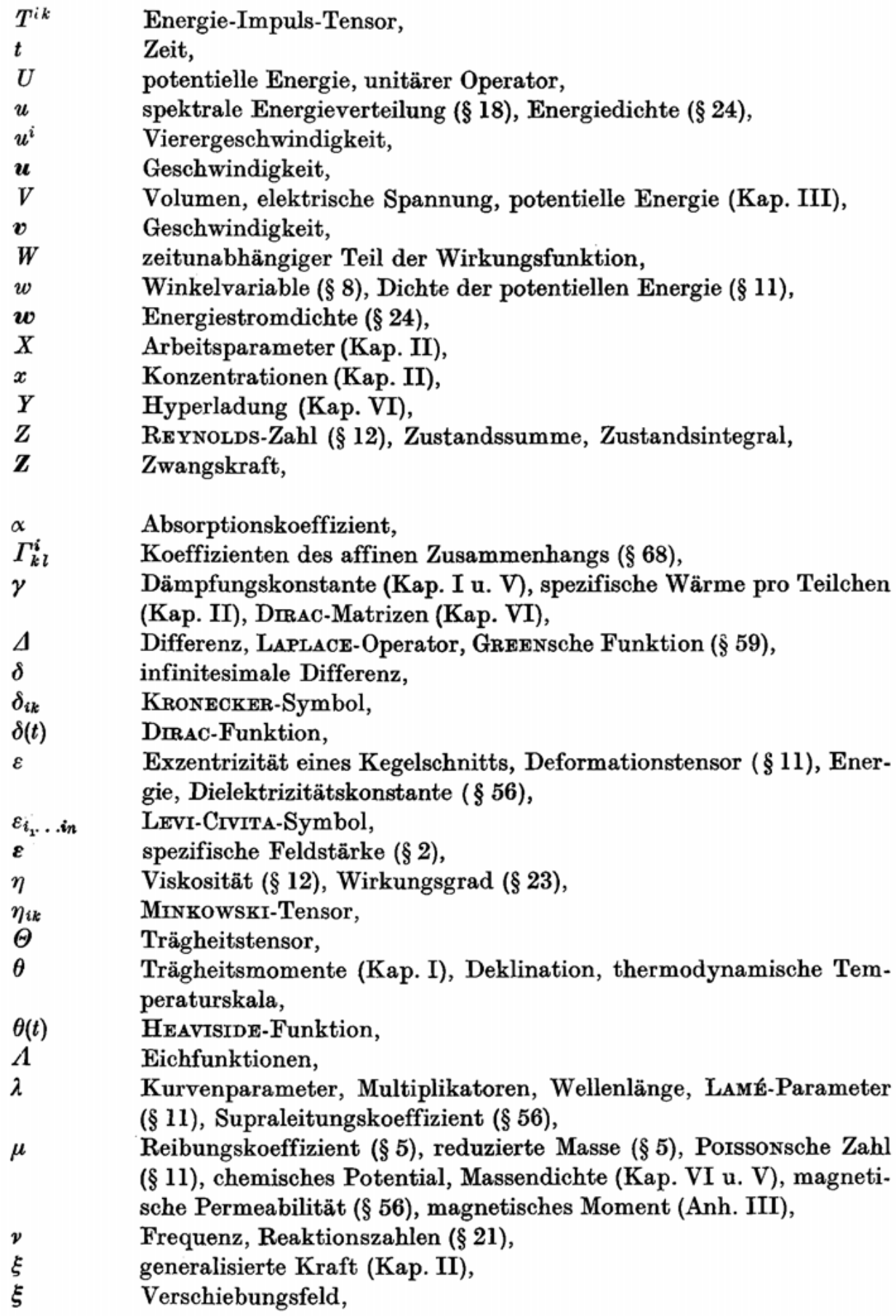




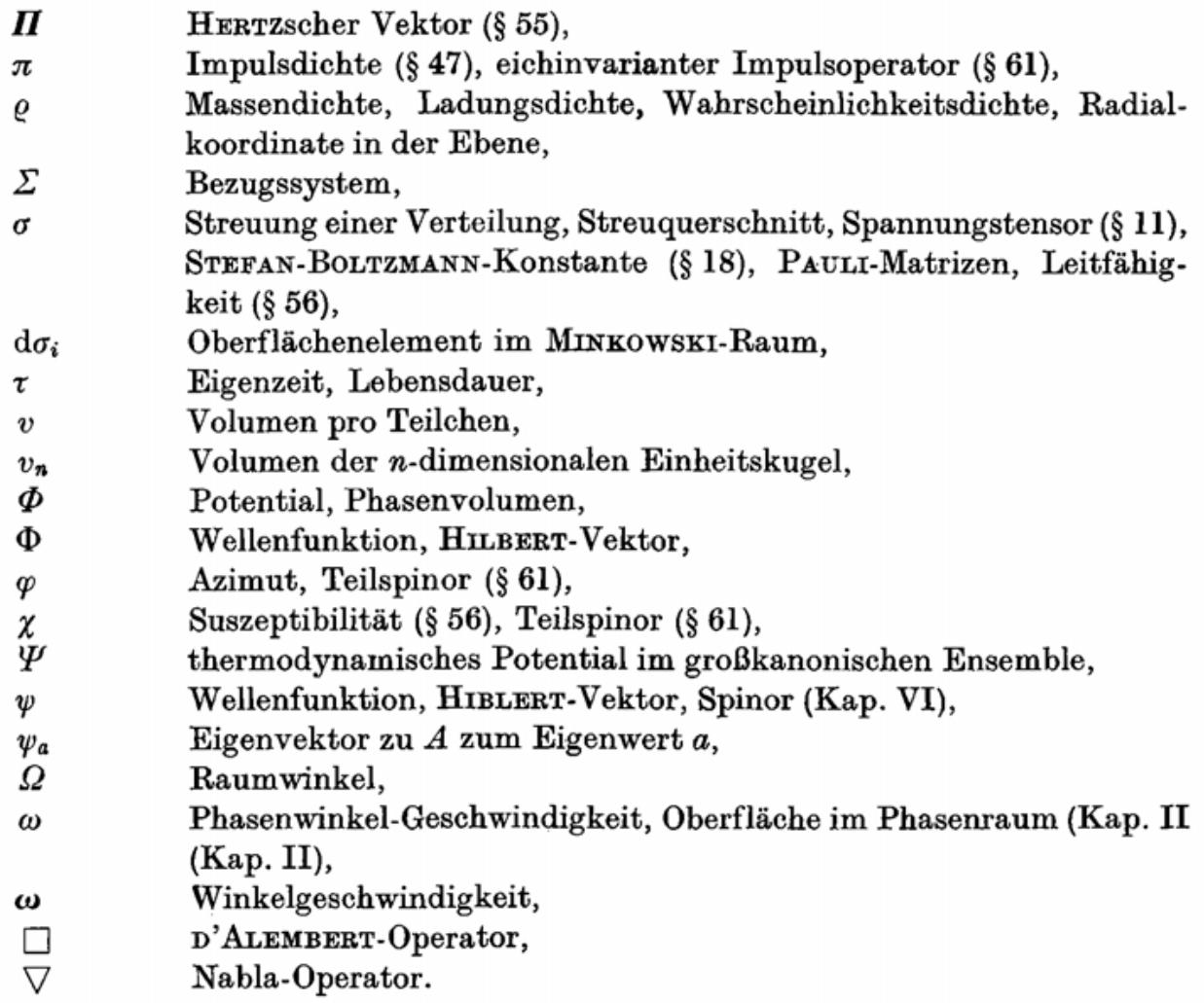

Ab Kapitel VI und in den Paragraphen 6, 8, 10, 11 und 12 wird die Ernsternsche Summationskonvention benutzt: Über zwei in einem Produkt auftretende Indizes wird summiert, ohne daß Summenzeichen geschrieben werden müssen.

Die partielle Ableitung nach der $i$-ten Koordinate wird an diesen Stellen durch ein Komma und die Angabe des Index beschrieben:

$$
\frac{\partial f}{\partial x^{i}}=f_{, i} \text {. }
$$

